\title{
BURLAS LITERARIAS DE ALFONSO REYES
}

Con frecuencia suele pensarse en el humanista como un ser ceñudo, deshumanizado entre la balumba de papelotes que compulsa, abstraído de la realidad y atento tan sólo a lo que escribe y escribe incansable. A ello puede impulsarnos la contemplación superficial del Erasmo de los pinceles de Metsijs,' de Holbein o de ese grabado en madera de 1526 que se conserva en la Biblioteca Real de Bélgica.

Hay humanistas ceñudos, amargados, sí. Pero el verdadero y cabal humanista no lo es. Vive plenamente su condición de hombre. Por eso no puede olvidar el "soy hombre y nada de lo que es humano me es ajeno", que nos dice el verso de Terencio.

Una carta de 1499 a Faustus Andrelinus nos muestra un Erasmo fascinado por la costumbre, "jamás alabada lo bastante" -dice él mismo-, que las inglesas tienen de recibir a alguien con besos y despedirlo con besos; de brindar besos a porfía. Insistente y lindamente lo dice en su latín: "propinantur suauia... diuiduntur basia... basiatur affatim". Y nos hace saber que entonces, entre tantos besos, saluda más cariñosamente, sonríe más afable: "salutat paulo blandius, arridet comius"'.

El Hitlodeo de la Utopía de Tomás Moro - gran amigo del roteródamo- es un bromista, amigo de chanzas. Moro, que también lo era, acuñó en efecto ese nombre del verbo $v \theta \lambda \lambda^{\epsilon} \omega$ que en griego vale bromear, chancearse. John Ruskin lo vio muy bien cuando en una carta de julio de 1870 agradece el envío de un ejemplar de la Utopia y manifiesta que ella "logra ser tal vez el libro

${ }^{1}$ Opus Epistolarum Des. Erasmi Roterodami. Denuo recognitum et auctum per P. S. Allen, M. A., Oxonii e Typographeo Clarendoniano, 1906, t. 1, carta 103, pp. 238-239.

NRFH, XXXVII (1989), núm. 2, 299-304 
realmente más travieso y bromista que se haya escrito, con excepción del Quijote"'?

De esa familia de humanistas sonrientes, juguetones, es $\mathrm{Al}$ fonso Reyes, quien afirma que "cuando el hombre sonríe, entonces funda la civilización y empieza la historia". Y Jaime Torres Bodet dijo que los libros del regiomontano "son un modelo de sonrisa y de claridad"'3. Modelo de sonrisa, sí. Pero hay momentos en los que como Erasmo "arridet comius", sonríe más afable. Son aquellos en que lo vemos interesado en cosas que otros humanistas ceñudos hubieran desdeñado. En dos ocasiones, una en verso y otra en prosa, nos dejó su profesión de fe al respecto.

En 1931 escribía:

Yo prefiero promiscuar en literatura.

Guardo mejor la salud alternando lo ramplón con lo fino, y junto en el alquitara - como yo sé-

el román paladino

del vecino

con la quintaesencia rara de Góngora y Mallarmét.

Trece años después reitera en prosa su postura: "Si he de decir todo lo que pienso, el que no sabe jugar con las letras me parece un arribista del alfabeto ya que no un analfabeto" 5 .

Ejemplos de tal actitud los hallamos muy claros en unas páginas de Los siete sobre Deva, sueño de una tarde de agosto, en las que juguetea sobre cómo llamar en español a los "clubs" o clavas del golf; o en tales otras de Árbol de pólvora y de Quince presencias; en los dos tomos de Las burlas veras o en esas preciosas Memorias de cocina y bodega.

Es que "Alfonso Reyes, hombre de su tiempo, no es como

${ }^{2}$ Sir Edward Tyas Cook, Life of John Ruskin, G. Allen, London, 1911, t. 1, p. 371 .

${ }^{3}$ CuA 19 (1963), p. 12. Palabras de Jaime Torres Bodet en la Rotonda de los Hombres Ilustres cuando el entierro de Alfonso Reyes.

4 "'Teoría prosaica", en Constancia poética, AROC, t. 10, p. 130. p. 114

${ }^{5}$ Transacciones con Teodoro Malio, en Ancorajes, Tezontle, México, 1951, 
los del antiguo sistema, que citaban a Virgilio para abrumar a sus pobres contemporáneos. Alfonso Reyes es muy capaz de citar a Jean Cocteau para aligerar a Lucano". Enrique Díez-Canedo, de quien son esas palabras ${ }^{6}$, escribió al alimón con Alfonso Reyes tres burlas literarias ${ }^{7}$. A ellas me contraigo, pues el tiempo no da para más. Ocioso sería tratar de deslindar la parte del mexicano y la parte del español. Ambos están en el todo y en el pormenor.

La primera burla atribuye a Julio Cejador y Frauca una traducción del soneto de Dante, en la Vita nuova, que comienza: "Tanto gentile e tanto onesta pare. . "' La mofa empieza desde la presentación. En ella leemos:

Este soneto trasladó a fuerza de redaños poéticos, quitándole alfeñicados perendengues y tapujos toscanos, a la reciedumbre de nuestra lengua, la más cimarrona y juncal del globo, aunque otras preñadas de nieblas le roan el zancajo, un historiador de ella y de su literatura, $\tan$ horro de los arrequives de la clerigalla por de fuera cuanto pergeñado de sus mataduras y garambainas por de dentro.

Ya en la traducción, el delicado primer verso del Alighieri cae en: "Tan gallarda y cerrera va mi moza". Va creciendo la burla y culmina en el último terceto. Donde Dante dice tiernamente:

e par che della sua labbia si mova un spirito soave e pien d'amore che va dicendo a l'anima: Sospira!

estalla el escarnio de lo siguiente:

$Y$ tanta enjundia en la persona lleva, Tan socarrona es que, ante un envite, Responde: - ¡Aprieta! - por decir: ¡Suspira!

La revista florentina La Rassegna de Áchille Pellizzari vio bien lo que esa versión paródica era y no dejó de subrayar su "scherzo spiritoso", su burla ingeniosa.

La segunda burla literaria toma pie en un soneto de Góngora

${ }^{6}$ Enrique Díez-Canedo, Letras de América, El Colegio de México, México, 1944, p. 246.

${ }^{7}$ Archivo de Alfonso Reyes, Serie B (Astillas), núm. 1, Burlas literarias 1919-1922, Impr. Barrié, México, 1947. 
al sepulcro del Greco ${ }^{8}$. Consiste en el pretendido descubrimiento de dos cartas del Greco al poeta y una de éste al pintor. Entre otras bromas, se les hace al cordobés y al candiota precursores del cubismo. Se pone en la pluma del autor de las Soledades lo siguiente: "Una esfera es la cabeza del hombre, y el tronco un cubo con sendos cylindros a diestra y siniestra"'. A ello contesta el pintor: "Piense vuesamerced lo que le dije del tronco de pyramide y de los dos cylindros a que la cara puede reducirse cuando no a un emisferio y a un cubo". Después de las cartas van dos párrafos de chocarreras notas con un tono de erudición.

Julio Cejador, humanista que no conocía la sonrisa, no entendió la burla. Escribe entonces su protesta, el 24 de agosto de 1921, a la revista Índice cuyo suplemento humorístico La rosa de papel había acogido las cartas con sus párrafos introductorios y notas. Señalo de pasada que Índice se publicaba al cuidado de Juan Ramón Jiménez y del propio Alfonso Reyes. Cejador, pues, truena diciendo que "las supercherías cuando no se publican en broma, sino muy en serio [...] pueden hacer mucho daño en la república de las letras'. Y muy orondo aduce que no había autoridad del XvI o del Xvn que avalase la expresión tanto más cuanto que.

Sigue la zumba al agradecer la carta del iracundo dómine diciendo, entre otras burlas, que "Góngora, precursor de tantas cosas, pudo muy bien serlo en ésa". Viene luego la puntilla al asentar: "Nosotros, hombres poco eruditos, pero bastante respetuosos, nos libraremos muy mucho de afirmar nada tocante a esas cartas. Sólo, adelantándonos a ciertas susceptibilidades, afirmamos con toda solemnidad que la carta del Sr. Cejador es auténtica...',

La última vaya que nos dan las Burlas literarias que vengo considerando nos lleva a la Edad Media. Esta vez es un humilde trapero que encuentra y entrega "dos fojas de pergamino graciosamente ornadas con miniaturas de la más fina escuela madrileña". Eso leemos en la "Noticia" introductoria. Contienen, nos dice la misma burlona "Noticia", un poema del Debate entre el vino $y$ la cerveza. Recuérdense, al respecto, los debates medievales entre el agua y el vino. Se transcriben luego los 135 versos del Debate. Los dos últimos rezan: "soli deo onor, et gloria / Alphonsus Henriquez me fecit". La nota correspondiente dice: "Adviértase que,

${ }^{8}$ Es el soneto 332, p. 430 de la ed. de las Obras completas de GónGORA por Juan Millé y Jiménez, Aguilar, Madrid, 1943. Alfonso Reyes lo tomó del f. 23 de la ed. de Hoces, 1654. 
para el autor de este poema, no tenía secretos la lengua latina". Como tampoco es un secreto para nosotros que Alphonsus es $\mathrm{Al}$ fonso Reyes, y Henriquez, Enrique Díez-Canedo.

En la lengua se mezclan con finura términos y construcciones del medioevo con otros actuales y aun con galicismos traídos aposta. El poema va seguido de unas notas sobre la fecha y el autor, el lenguaje y la versificación, amén de otras veinte a otros tantos versos, llenas de humor. Las notas a los versos 119 y 120 nos explican quiénes son esos bebedores de cerveza que se nombran "piebolistas, alienistas e socialistas". Las de estos dos últimos acotan: "diversas actitudes ante la vida". La de los primeros, "piebolistas", trae: "atletas laureados en los Juegos Olímpicos". Y añade, muy en serio: "Véase Murray, Greek sport in the vth Century and after, foot ball, etc., Oxford, 1923". Libro inexistente, claro. No así el helenista inglés, verdadero profesor regio de griego en $\mathrm{Ox}$ ford. Burla también la hay en las fechas. El supuesto libro de Gilbert Murray es de 1923 y el famoso Debate de 1921. Se publicó, en efecto, en 1921, en La Sirenita del Mar, suplemento (humorístico) número 3 del mismo número de la revista Índice.

Se menciona a Ramón e Caxal (esto es, Ramón y Cajal), que rima con "la neurona e todo lo al". Se habla, con humor un tanto negro, de "Abailardo que en Luteçia / de ser varón non se preçia". No falta la pulla contra Cejador cuando "donna cerueça" dice al hermano vino:
Acaso te beue algún cura que ya non rapa tonsura, xaqueta larga e muy tozudo, por cabeza una olla de engrudo, desque non te beue en la Missa te halla sabor a su guissa.

En las notas de socarrona erudición, escritas con donaire, yo quiero ver una irónica protesta de Reyes - a la manera del Prólogo al primer Quijote - contra la erudición huera y falsa, a la par que contra las notas a destiempo y traídas por los cabellos.

Nos confirman esas Burlas literarias el "Yo prefiero promiscuar / en literatura", al igual que el consejo de saber "jugar con las letras". Que en otro contexto, pero en la misma línea, había dicho una verdad de a puño. He aquí, para terminar, lo que afirmaba don Alfonso: 
Hoy por hoy, el excesivo desarrollo de lo "libresco" — valga la palabreja - hace que la gente olvide el valor "intelectual" de lo que no está embarrado en los libros. Una granja, una fábrica, el árbol de un motor, una carretilla o volquete, una caña de pescar, no se ven como una conquista de la inteligencia; - digo, por el vulgo con letras, el más antipático de los vulgos ${ }^{9}$.

Manuel Alcalá 